\title{
A global view of atmospheric ice particle 1 complexity
}

DOI:

10.1002/2016GL071267

\section{Document Version}

Accepted author manuscript

Link to publication record in Manchester Research Explorer

\section{Citation for published version (APA):}

Schmitt, C., Heymsfield, A. J., Connolly, P., Jarvinen, E., \& Schnaiter, M. (2016). A global view of atmospheric ice particle 1 complexity. Geophysical Research Letters, 43(22), 11913-11920. https://doi.org/10.1002/2016GL071267

\section{Published in:}

Geophysical Research Letters

\section{Citing this paper}

Please note that where the full-text provided on Manchester Research Explorer is the Author Accepted Manuscript or Proof version this may differ from the final Published version. If citing, it is advised that you check and use the publisher's definitive version.

\section{General rights}

Copyright and moral rights for the publications made accessible in the Research Explorer are retained by the authors and/or other copyright owners and it is a condition of accessing publications that users recognise and abide by the legal requirements associated with these rights.

\section{Takedown policy}

If you believe that this document breaches copyright please refer to the University of Manchester's Takedown Procedures [http://man.ac.uk/04Y6Bo] or contact uml.scholarlycommunications@manchester.ac.uk providing relevant details, so we can investigate your claim.

\section{OPEN ACCESS}




\section{A global view of atmospheric ice particle complexity}

3 Carl G. Schmitt ${ }^{1}$, Andrew J. Heymsfield ${ }^{1}$, Paul Connolly ${ }^{2}$, Emma Järvinen ${ }^{3}$, Martin

$4 \quad$ Schnaiter ${ }^{3}$

$5{ }^{1}$ National Center for Atmospheric Research, 3450 Mitchell lane, Boulder, Colorado, 80301,

6 USA.

$7 \quad{ }^{2}$ University of Manchester, School for Earth, Atmosphere and Environmental Sciences, Oxford

8 road, Manchester, England.

$9{ }^{3}$ Karlsruhe Institute of Technology, Institute for Meteorology and Climate Research,

10 Atmospheric Aerosol Research, Karlsruhe, Germany.

12 Corresponding author: Carl Schmitt (schmittc@,ucar.edu)

13 National Center for Atmospheric Research

143450 Mitchell Lane,

15 Boulder, CO, 80301, U.S.A.

16 Phone: (303) 497-8905

\section{Key Points:}

- Ice particle complexity is parameterized by temperature and cloud type.

- Ten datasets show common trends by cloud type. 


\section{Abstract}

Atmospheric ice particles exist in a variety of shapes and sizes. Single hexagonal crystals like common hexagonal plates and columns are possible, but more frequently, atmospheric ice particles are much more complex. Ice particle shapes have a substantial impact on many atmospheric processes through fall speed, affecting cloud lifetime, to radiative properties, affecting energy balance to name a few. This publication builds on earlier work where a technique was demonstrated to separate single crystals and aggregates of crystals using particle imagery data from aircraft field campaigns. Here, data from 10 field programs have been analyzed and ice particle complexity parameterized by cloud temperature for arctic, mid-latitude (summer and frontal), and tropical cloud systems. Results show that the transition from simple to complex particles can be as small as 80 microns or as large as 400 microns depending on conditions. All regimes show trends of decreasing transition size with decreasing temperature. 
34 Index terms and Keywords:

35 Atmospheric composition and structure:

36

37

38

39

40

41 Cloud ice snow

42 Ice particle habits

43 Ice particle complexity

\section{Keywords:}

Aerosols and particles

Cloud physics and chemistry

Cloud/radiation interaction

Instruments and techniques 
1 Introduction

Weather forecast and General Circulation Models (GCMs) need to accurately represent the characteristics of atmospheric ice particles for accurate forecasts. Atmospheric ice particle properties vary widely in shape and size due to changing growth regimes in different temperatures regimes. Some modeling schemes characterize atmospheric ice as "cloud ice" or "snow" yet the transition between these particle types is poorly understood [Morrison and Grabowski, 2008]. Waliser et al. [2009] point out that cloud processes in GCMs have become more sophisticated in recent years in their treatment of ice particles, yet these changes have been largely independent of measurements. Jiang et al. (2012) showed that for 19 GCMs, the model spreads and differences were most significant in the upper troposphere where ice clouds are prevalent as compared to the lower and middle troposphere. In natural ice clouds, ice particle complexity $(C)$ has been used to explore the transition from single ice crystals to complex particles [Schmitt and Heymsfield, 2014, hereafter SH14]. The SH14 technique uses particle imagery analysis of aircraft microphysical probe measurements. In this study we have applied this technique to numerous datasets from around the world to better quantify the transition from simple to complex particle in different regions by temperatures.

Ice particle complexity is highly dependent on how ice particles grow in the atmosphere. Vapor growth of ice crystals has been studied for decades [Ryan et al. 1976] and is well characterized. This type of study has led to schemes such as the Adaptive Habit Model [Sulia et al. 2013] which uses temperature to predict the growth by vapor of ice crystals and the capacitance model [Westbrook et al. 2008]. In natural clouds, processes such as differential fall speeds lead to aggregation of ice particles. Ice particle aggregation and riming lead to highly 
67 irregular shapes [Ono, 1969]. Though the processes leading to these complex shapes are well understood, most cloud modeling techniques have not advanced sufficiently to include these growth processes.

Observations in natural clouds confirm that complex particle shapes including aggregates are common. A study by Korolev et al. [1999], using high resolution imagery from the Stratton Park Engineering Company (SPEC Inc.) Cloud Particle Imager (CPI) probe [Lawson et al. 2001] showed that only 3\% of Arctic ice cloud particles were pristine. Stoelinga et al. [2007] pointed out that aggregates of ice crystals often included components that can be readily classified using the Magono and Lee [1966] classification scheme. The Magono and Lee [1966] classification scheme includes 80 particle types, yet many types are quite complex while Korolev et al. [1999] classify four vapor grown habits.

In this paper a global dataset including data from 10 field programs is used to identify the transition between levels of ice particle complexity. The results of these analyses will help inform on atmospheric ice particle growth and its variability. These results will also be useful to radiation transfer calculations such as Liu et al. [2014] who use two ice particle types for their model as well as Baum et al. [2011]. In section 2, the analysis technique presented in SH14 will be reviewed and a parameterized fit scheme is introduced. In section 3, results from datasets which were manually classified are compared to the automatic classification schemes. In section 4, results from the global datasets are presented and parameterized. Conclusions and implications are discussed in section 5.

\section{Analysis techniques}


The visual appearance of atmospheric ice particles has been used to calculate a complexity value $(C)$. Previously, SH14 defined ice particle complexity as:

$$
C=10 *\left(0.1-\frac{\sqrt{A_{c} A_{p}}}{P^{2}}\right)
$$

where $A_{C}$ is the area of the circle with the smallest area which will cover the particle, $A_{P}$ is the projected area of the particle, and $P$ is the perimeter of the particle. Using a cutoff of $C=0.22$, SH14 showed that it was possible to separate simple, possibly single crystals from more complex, possibly aggregates of ice crystals. As stated in SH14, this complexity value led to minimal miss-classifications $(10 \%)$ with theoretically generated particles at random orientations. The reader is advised to use caution when using different values of $C$ with different datasets as some of the values in eq. 1 are sensitive to probe resolution. An appropriate $\mathrm{C}$ value may be significantly different for a different probe because of different methods for calculating the parameters (especially perimeter) as well as different imaging characteristics. Using a $C=0.22$ for CPI probe data showed that the transition from simple to complex particles as a function of particle size is a smooth function. Figure 1 shows two example datasets with sorted values of $C$ on the ordinate axis and particle size on the abscissa. The transition size (stepped line) can easily be described with a hyperbolic tangent function (eq. 2).

$$
\text { Percent }=100 *\left(\frac{\operatorname{Tanh}\left(\frac{D}{D_{t}}-S\right)}{2}+0.5\right)
$$

where $D$ is the particle maximum dimension, and $D_{t}$ is the transition size where the shift occurs from the majority being lower complexity particles to majority being higher complexity. $S$ is a measure of how quickly the change happens. The hyperbolic tangent fit lines (smooth lines) are also shown in figure 1. Using eq. 2 to create fit lines leads to $D_{t}$ values of 84 and 315 microns for data in panels a and $\mathrm{b}$. Also shown in figure 1 are three examples of how the different parameters in equation 2 affect the functional form. As can be seen in figure 1, the hyperbolic 
112 tangent fit to the raw data crosses the $50 \%$ mark at approximately at the size $\left(D_{t}\right)$ where the raw

113 data does. It was found that it was necessary to have at least 100 particles larger than 100

114 microns in order to get a good fit. The plots in figure 1 were calculated from 24000 and 1200

115 particles larger than 100 microns and included 1000 and 20 particles per ten micron bin at $D_{t}$

116 (AIRS and ARM respectively). Fitting hyperbolic tangent curves to the complexity data is a

117 good way to identify a quantifiable transition particle size.

118

\subsection{Fractal particles from complexity}

The complexity of observed particles can vary continuously. In addition to defining the transition from simple to complex (as in figure 1), it is possible to present particle complexity as a function of size and complexity. Figure 2 shows the same two examples except the complexity values have been colorized to show the variation of complexity. For each 10 micron size bin, the observed particles were sorted by complexity value. Each complexity value was then assigned a color. In these examples, $C=0$ is blue and $C=1$ being red. The transition complexity value where the switch generally takes place from a single crystal to early aggregates $(C=0.22)$ is in the blue range, but it can be observed that there is generally a smooth transition of colors in each size bin. The Ice Particle Aggregation Simulator (IPAS) model which was developed for Schmitt and Heymsfield [2010] and used in SH14 to study complexity can be used to understand the observations in figure 2. Using IPAS, the complexity range for aggregates of any number of components crystals can be estimated. While not all complex particles in the atmosphere are aggregates (bullet rosettes and dendrites for example), using images of aggregates is useful for understanding the three dimensional characteristics relate to what is observed (two dimensional images). Figure 3 shows the mean and standard deviation of $C$ for aggregates with between 1 and 9 components. Also shown in Figure 3 is the average aggregate size relative to monomer size 
135 for IPAS particles with different numbers of components. Note that the mean $C$ values are

136 initially reasonably separated, but as the number of components increases, there is overlap in the

$137 C$ values. As eq. 1 includes several particle measurements that can be used in identifying fractal

138 properties [Falconer, 2003], it is suggested that aggregates with 6 or more components are

139 sufficiently indistinguishable and are likely to be sufficiently fractal to adhere to standard fractal

140 relationships (eg. power law mass and area dimensional relationships). Schmitt and Heymsfield

141 [2010] showed that ice particle aggregates generally became fractal in dimensional

142 characteristics once the aggregates had approximately 10 components which agrees reasonably

143 with the complexity argument. Using this information, particles with $C>0.6$ are likely to be

144 fractal.

145

146

147

148

149

150

151

152

153

154

155

156

157

\section{Manual classification}

For three datasets, manual particle classification has been done in order to validate automatic algorithms. Figure 4 shows the complexity plotted versus size for the three datasets. For each of the datasets, particles have been separated into single particles or complex particles by manual inspection as well as by the automated $C$ classification. Blue points represent particles which were manually classified as single crystals and red points represent more complex particles. The black and red stepped lines represent the percentage of particles that are classified as simple for logarithmically spaced size bins. The black is for the automatic classification and red is for the manual classification. Note that these curves are the inverse of those shown in figure 1 so that the lines do not interfere with the data points.

The first dataset is composed of approximately 500 particles during a flight from the 9 March 2000 ARM IOP over Oklahoma. The clouds sampled were mostly composed of bullet 
rosettes with some aggregates of bullet rosettes as well as some small columns. The second dataset is composed of approximately 500 particles measured during a flight from the 26 July 2002 CRYSTAL-FACE field project in Florida where most of the particles were aggregates of small crystals. The third plot shows only data from bullet rosettes classified during the ARM case. Different colors are used to represent different ranges for the number of bullets in the rosette. The data from SH14 as well as other data analyzed in this work are from the CPI probe. The final dataset was collected using the Particle Habit Imaging and Polar Scattering (PHIPS) instrument developed at the Karlsruhe Institute of Technology [Abdelmonem et al. 2011]. The PHIPS has similar resolution than the CPI, and the results are quite similar. This dataset is composed of 14000 particles measured during the ACRIDICON-CHUVA project in Brazil [Wendisch et al. 2016]. The cluster of points stretching from 10 to 100 microns which is composed mostly of single particles has a moderate slant upwards in complexity values. This is likely due to slight differences in the way the different parameters are calculated by PHIPS. For this dataset, $C=0.3$ was used rather than 0.22 for the automatic classification. The three datasets show that the automatic classification and manual classification generally agree well.

\section{Global analysis}

For the datasets analyzed, several precautions were taken to assure high quality data. Data were analyzed using “CPIview” software written by Stratton Park Engineering Corp (SPEC Inc.). Particle images were only used if the particle was the only particle in the CPI frame reducing the likelihood of shattered particles being inadvertently included in the analysis. Particles with focus values of less than 45 were not used and particles that touched the edge of 
180 the field of view were not used (McFarquhar et al, 2013). Figures 1 and 2 show two cases where

181 there was an extreme difference in the transition size from simple to complex particles.

182

183

184

185

186

187

188

189

190

191

192

193

194

195

196

197

198

199

200

201

202
Here we present results from 10 field programs around the globe. Field programs were separated into four different types: Arctic, Mid-latitude summer, Mid-latitude frontal, and Tropical.

\section{1 field programs}

Arctic field programs include: The Aerosol Cloud Coupling And Climate Interactions in the Arctic [ACCACIA, Lloyd et al. 2015] and the Mixed Phase Arctic Cloud Experiment [MPACE, Verlinde et al. 2007].

Mid-latitude summer field programs include: The Atmospheric Radiation Measurements Intensive Operating Period [ARM-IOP, Heymsfield et al. 2002]. the Midlatitude Cirrus Cloud Experiment (MIDCIX, Heymsfield et al. 2006), and the Egrett Microphysics Experiment with RAdiation, Lidar, and Dynamics [EMERALD, Whiteway et al. 2004].

Mid-latitude frontal field programs include: The Alliance Icing Research Study II

[AIRS2, Isaac et al. 2004], and the Ice in Clouds Experiment - Layers [ICE-L, Heymsfield et al. $2011]$.

Tropical field programs include: The Aerosol and Chemical Transport in Deep Convection [ACTIVE, Vaughan et al. 2008], the Cirrus Regional Study of Tropical Anvils and Cirrus Layers - Florida Area Cirrus Experiment [CRYSTAL-FACE, Jensen et al. 2004], and the Ice in Clouds Experiment - Tropical [ICE-T, Heymsfield and Willis, 2014].

\subsection{Results}

In order to present data in a statistically representative way, the following procedure was used. For each field program type, $D_{t}$ was calculated for all particles sampled during each of the 
individual flights at $5^{\circ} \mathrm{C}$ temperature blocks through the observed clouds. When there were sufficient particles, the value of $D_{t}$ was determined and included in the study. This led to an array of $D_{t}$ values with the different flight days on one axis and the different temperature ranges on the other axis filled with $D_{t}$ values for each field program. All of the $D_{t}$ values for a particular temperature range from each field program classification were averaged and the standard deviation was determined (the standard deviation was calculated when there were at least 5 data points available). Figure 5 shows the vertical profiles of $D_{t}$ and with plus and minus the standard deviation shown. A fit line is also plotted on the figures. The parameters for the fit lines are given on the figures. As can be seen in figure 5, all cloud types display a trend of decreasing $D_{t}$ with decreasing temperature. The slope of the trend in arctic and frontal datasets was not as steep as for the tropical and midlatitude summer datasets. Cloudtop temperature likely plays a role in this as tropical and midlatitude clouds often reach colder cloudtop temperatures due to higher tropopause altitudes. The $S$ parameter in equation 2 did not show any significant trends with temperature and was generally 2.5 plus or minus 0.5 .

The transfer of particles from early aggregates to fractal aggregates was estimated with fractal particles being defined as having $C$ values higher than 0.6 . In this case, data are averaged for the different temperature blocks for each of the field programs as there often were not sufficient large particles to get a good fit to the data for an individual temperature block for a single flight. This value was then compared to the $D_{t}$ for transitioning from single to complex particles. The results suggest that there is a reliable relationship between the two transition points that doesn't vary environmentally. For the full dataset, the transition to fractal particles occurs at 3.3 times $D_{t}$ with a standard deviation of 0.9 . The only significant exception to this 
was for the midlatitude summer cases where bullet rosette shaped particles were the dominant particle shape. The relationship for these cases averaged 2.6.

The factor of 3.3 difference between $D_{t}$ and the transition to fractal particles agrees reasonably with the results from IPAS which showed that an aggregate of six monomers averaged 2.7 times the average size of an individual monomer (figure $3 \mathrm{~b}$ ). Note that the sizes of the IPAS aggregates are determined by averaging the maximum dimension from theoretical images of the IPAS aggregates, not the true maximum dimension. This is done so that the IPAS results can be directly compared to the data from aircraft probes which do not measure the true maximum dimension. The discrepancy between IPAS and measurement results (3.3 versus 2.7) is likely due to the fact that atmospheric ice particles can continue to grow from vapor while IPAS particles are not grown during the theoretical aggregation process.

\section{Summary}

In this publication we present the results of the analysis of microphysical data from ten field programs to characterize the transition of complexity of ice particles. Results demonstrate that particles in different regions have predictable characteristics based on cloud temperature. Tropical and mid-latitude summer datasets generally showed similar trends while mid-latitude frontal and arctic datasets were similar. The mid-latitude summer and tropical are likely different due to convective storms being more common in these regions.

For all cases the transition size decreases with decreasing temperature from 190-240 microns at $0^{\circ} \mathrm{C}$ to less than 100 microns at the coldest temperatures in some regions. The transition size is easily parameterized with linear fit parameters through the troposphere. Ice 
247 particles tend to have fractal characteristics when they are $3.3 \pm 0.9$ times larger than the

transition from single to complex. This ranges from 300 microns up to 750 microns.

Results will be useful for radiation transfer research as well as for modeling applications.

As the light scattering properties of ice clouds can be characterized using simple and complex particles [Liu et al. 2014], this finding will be useful for parameterizing the light scattering properties of clouds in climate models. Liu et al. [2014] used a fixed cutoff size which could be advanced by including a variable cutoff size based on atmospheric temperature. Modeling studies can benefit from this research ice particle properties can be easily parameterized by temperature which will lead to better characterization of ice particle properties especially in models that do not have the resolution to include cloud processes.

\section{Acknowledgments}

This work was supported by NASA MACPEX research project funding, Hal Maring program manager under contract \#NNX11AC07G, and the German Research Foundation (DFG) within HALO priority program 1294 (contract SCHN 1140/1-2). Additional support came from the National Science Foundation's Center for Multi-Scale Modeling of Atmospheric Processes (CMMAP) managed by the Colorado State University under agreement ATM-0425247. Funding for ACTIVE and ACCACIA were from the Natural Environment Research Council, grant NE/C512688/1 (ACTIVE) and NE/I028696/1 (ACCACIA), data available at http://badc.nerc.ac.uk/home/index.html. EMERALD data are available from Connolly. ACRIDICON-CHUVA data are available from Schnaiter. CRYSTAL-FACE, MidCIX data are available at: https://espoarchive.nasa.gov/archive/browse. ARM-IOP and MPACE data are available at: http://archive.arm.gov. ICE-L, ICE-T and AIRS2 data are available at: https://www.eol.ucar.edu/all-field-projects-and-deployments. 


\section{References}

Abdelmonem, A., M. Schnaiter, P. Amsler, E. Hesse, J. Meyer, and T. Leisner (2011), First correlated measurements of the shape and light scattering properties of cloud particles using the new Particle Habit Imaging and Polar Scattering (PHIPS) probe, Atmos. Measur. Tech., 4, 2125-2142.

Baum, B. A., P. Yang, A. J. Heymsfield, C. G. Schmitt, Y. Xie, A. Bansemer, Y-H. Hu, Z. Zhang (2011), Improvements to shortwave bulk scattering and absorption models for the remote sensing of ice clouds, J. Appl. Meterol. and Climatol., 50, 1037-1056.

Falconer, K. (2003), Fractal Geometry Mathematical Foundations and Applications. Wiley, 337 pp.

Heymsfield, A. J., S. Lewis, A. Bansemer, J. Iaquinta, L. Milosovich, M. Kajikawa, C. Twohy, and M. Poellot (2002), A general approach for deriving the properties of cirrus and stratiform ice cloud particles. J. Atmos. Sci., 59, 3-29.

Heymsfield, A. J., C. Schmitt, A. Bansemer, G-J. Zadelhoff, M. J. McGill, C. Twohy, and D. Baumgardner (2006), Effective radius of ice cloud particle populations derived from aircraft probes. J. Atmos. Oceanic Technol., 23, 361-380.

Heymsfield, A. J., P. R. Field, M. Bailey, D. Rogers, J. Stith, C. Twohy, Z. Wang, S. Haimov (2010), Ice in clouds experiment - Layer clouds. Part I: Ice growth rates derived from lenticular wave cloud penetrations, J. Atmos. Sci., 68, 2628-2654.

Heymsfield, A. J., and P. Willis (2014), Cloud Conditions Favoring Secondary Ice Particle Production in Tropical Maritime Convection, J. Atmos. Sci., 71, 4500-4526.

Jensen, E. J., D. Starr, and O. B. Toon (2004), CRYSTAL-FACE mission, Eos Trans. AGU, 85, $45-50$. 
Jiang, J. H. and co-authors (2012) Evaluation of cloud and water vapor simulations in CMIPS5 climate models using NASA “A-Train” satellite observations, J. Geophys. Res., 117, D14105, doi: 10.1029/2011JD017237.

Korolev, A. V., G. A. Isaac, and J. Hallett (1999), Ice particle habits in arctic clouds, Geophys. Res. Lett., 26, 1299-1302.

Lawson, R.P., B.A. Baker, C.G. Schmitt, and T.L. Jensen (2001), An overview of microphysical properties of Arctic clouds observed in May and July 1998 during FIRE ACE. $J$. Geophys. Res., 106, 14,989-15,014.

Liu, C., P. Yang, P. Minnis, N. Loeb, S. Kato, A. Heymsfield, and C. Schmitt (2014), A twohabit model for the microphysical and optical properties of ice clouds. Atmos. Chem. Phys. 14, 13719-13737.

Lloyd, G., T. W. Choularton, K. N. Bower, J. Crosier, H. Jones, J. R. Dorsey, M. W. Gallagher, P. Connolly, A. C. R. Kirchgaessner and T. Lachlan-Cope (2015), Observations and comparisons of cloud microphysical properties in spring and summertime Arctic stratocumulus clouds during the ACCACIA campaign, Atmos. Chem. Phys., 15, 37193737, doi:10.5194/acp-15-3719-2015.

Magono, C., and C. W. Lee (1966), Meteorological classification of natural snow crystals, $J$. Fac. Sci. Hokkaido Univ. Ser. VII, 2, 321-362.

McFarquhar, G. M., J. Um, and R. Jackson, 2013: Small cloud particle shapes in mixed- phase clouds. J. Appl. Meteor. Climatol., 52, 1277-1293. 
Morrison, H., and W. W. Grabowski (2008), A novel approach for representing ice microphysics in models: Descripting and tests using a kinematic framework, J. Atmos. Sci., 65, 15281548.

Ono, A. (1969), The shape and riming properties of ice crystals in natural clouds, J. Atmos. Sci., 26, 138-147.

Ryan, B. F., E. R. Wishart, and D. E. Shaw (1976), The growth rates and densities of ice crystals between $-3^{\circ} \mathrm{C}$ and $-21^{\circ} \mathrm{C}$, J. Atmos. Sci, 33, 842-850.

Schmitt, C. G., and A. J. Heymsfield (2010), Dimensional characteristics of ice crystal aggregates from fractal geometry, J. Atmos. Sci., 67, 1605-1616.

Schmitt, C. G., and A. J. Heymsfield (2014), Observational quantification of the separation of simple and complex atmospheric ice particles, Geophys. Res. Lett. 41(4), 1301-1307.

Stoelinga, M. T., J. D. Locatelli, and C. P. Woods (2007), The occurrence of "irregular" ice particles in stratiform clouds, J. Atmos. Sci., 64, 2740-2750.

Sulia, K., J. Y. Harrington, and H. Morrison (2013), A method for adaptive habit prediction in bulk microphysical models: Part III: Applications and studies within a two-dimensional kinematic model. J. Atmos. Sci., 64, 70 (10), 3302-3320, doi: 10.1175/JAS-D-12-0316.1.

Vaughan, G., C. Schiller, A. R. MacKenzie, K. Bower, T. Peter, H. Schlager, N. R. P. Harris, and P. T. May (2008), SCOUTO3/ACTIVE: High-altitude aircraft measurements around deep tropical convection, B. Am. Meteorol. Soc., 89, 647-662, doi: 10.1175/BAMS-89-5647.

Verlinde, J., J. Y. Harrington, G. M. McFarquhar, V. T. Yannuzzi, A. Avramov, S. Greenberg, N. Johnson, G. Zhang, M. R. Poellot, J. H. Mather, D. D. Turner, E. W. Eloranta, B. D. Zak, A. J. Prenni, J. S. Daniel, G. L. Kok, D. C. Tobin, R. Holz, K. Sassen, D. 
Spangenberg,P. Minnis, T. P. Tooman, M. D. Ives, S. J. Richardson, C. P. Bahrmann, M. Shupe, P. J. Demott, A. J. Heymsfield, and R. Schofield (2007), The mixed-phase arctic cloud experiment, Bull. Am. Meterol. Soc. 88, 205-221, DOI:10.1175/BAMS-88-2-205.

Waliser, D. E., J-L. F. Li, C. P. Woods, R. T. Austin, J. Bacmeister, J. Chern, A. Del Genio, J. H. Jiang, Z. Kuang, H. Meng, P. Minnis, S. Platnick, W. B. Rossow, G. L. Stephens, S. SunMack, W-K, Tao, A. M. Tompkins, D. G. Vane, C. Walker, and D. Wu (2009), Cloud ice: a climate model challenge with signs and expectations of progress, J. Geophys. Res. 114, DOI:D00A21, doi:10.1029/2008JD010015.

Wendisch, M. et al. (2016). The ACRIDICON-CHUVA campaign: Studying tropical deep convective clouds and precipitation over Amazonia using the new German research aircraft HALO. Bull. Am. Meterol. Soc., 160128144638003. http://doi.org/10.1175/BAMS-D-14-00255.1.

Westbrook, C. D., R. J. Hogan, and A. J. Illingworth (2008), The capacitance of pristine ice crystals and aggregate snowflakes, J. Atmos. Sci., 65, 206-219. 
Figure captions:

Figure 1: Panels a and $\mathrm{b}$ show two examples of ice particle complexity from aircraft data using the $C=0.22$ as a cutoff between 'simple' and 'complex' particles. The stepped line represents the percentage of complex particles in each $10 \mu \mathrm{m}$ size bin from each day of the indicated research flights. The smooth curve is the hyperbolic tangent fit to the data. The bottom row shows the effect of changing the different parameters in the hyperbolic tangent fit equation (eq. 2).

Changing $S$ (panel c) moves the curves side to side. Changing $D_{t}$ (panel d) changes the shape as well as the placement of the $50 \%$ intersect in the curve. To keep the same $D_{t}$ cutoff, $D_{t}$ and $S$ must be changed together as in panel e so that for each $D, D / D_{t}-S$ is constant.

Figure 2: The same two examples as in figure 1, except that the $C$ values are represented by different colors running from blue $(C=0)$ to red $(C=1)$. This shows that there is a relatively uniform transition in complexity in each given size bin.

Figure 3: Results from IPAS simulations. Panel a shows the average $C$ value for IPAS particles with 1 to 9 component crystals as well as plus and minus the standard deviation. Note that there is much more overlap with higher numbers of components. Panel b shows the size of IPAS aggregates divided by the average single crystal size for aggregates with different numbers of components.

Figure 4: Hand analysis for several datasets. Particle complexity value is plotted versus maximum dimension. In panels $\mathrm{a}, \mathrm{b}$, and $\mathrm{d}$, the particles which were hand identified as single crystals are represented by blue dots while the particles hand identified as complex are represented by red dots. In panel c, the complexity of bullet rosette shaped crystals is plotted with respect to maximum dimension. Bullets with fewer than 4 bullets are green, 4 to 5 bullets are red, and more than 5 are represented by blue dots. In panels a, b, and d, the black and red 
375 lines indicate the proportion of particles in the size range which were classified as single

376 particles by hand (red) or by automatic classification (black), scale on the right

377 Figure 5: Observed trends $D_{t}$, the transition size between 'simple' and 'complex' atmospheric

378 ice particles in datasets separated into sampling regions. Stars represent average values for each

379 temperature layer with standard deviation spreads when sufficient data are available. Equation

380 for the fit lines are given. 

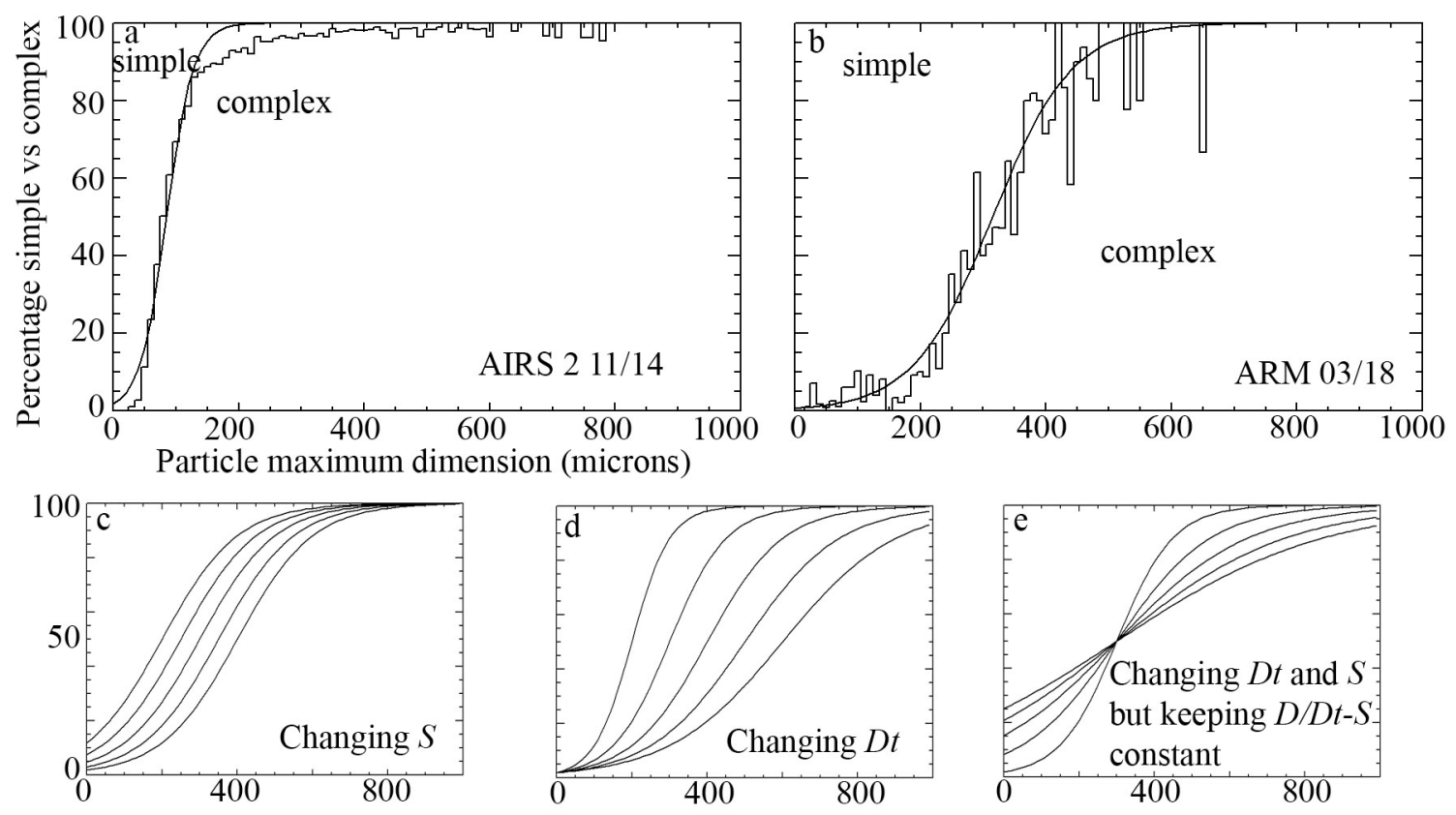

Particle maximum dimension (microns)

382

383

384 


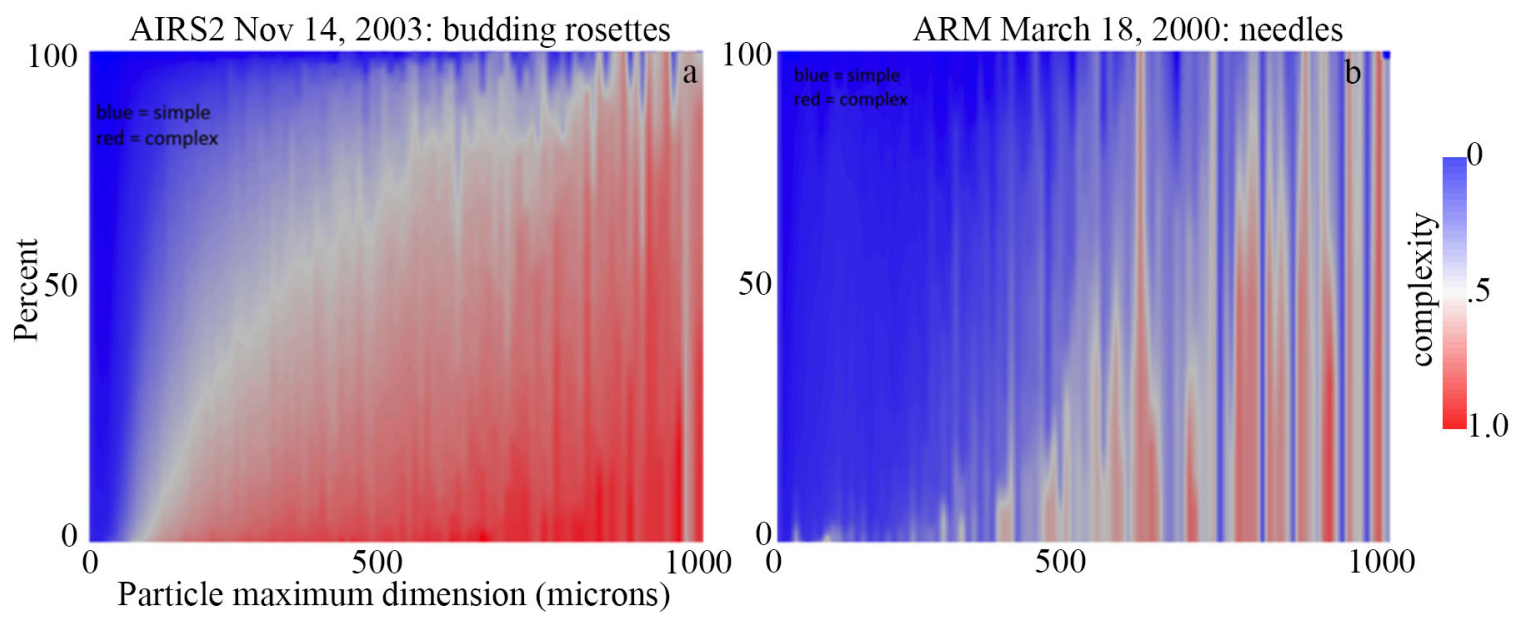




\section{Confidential manuscript submitted to Geophysical Research Letters}
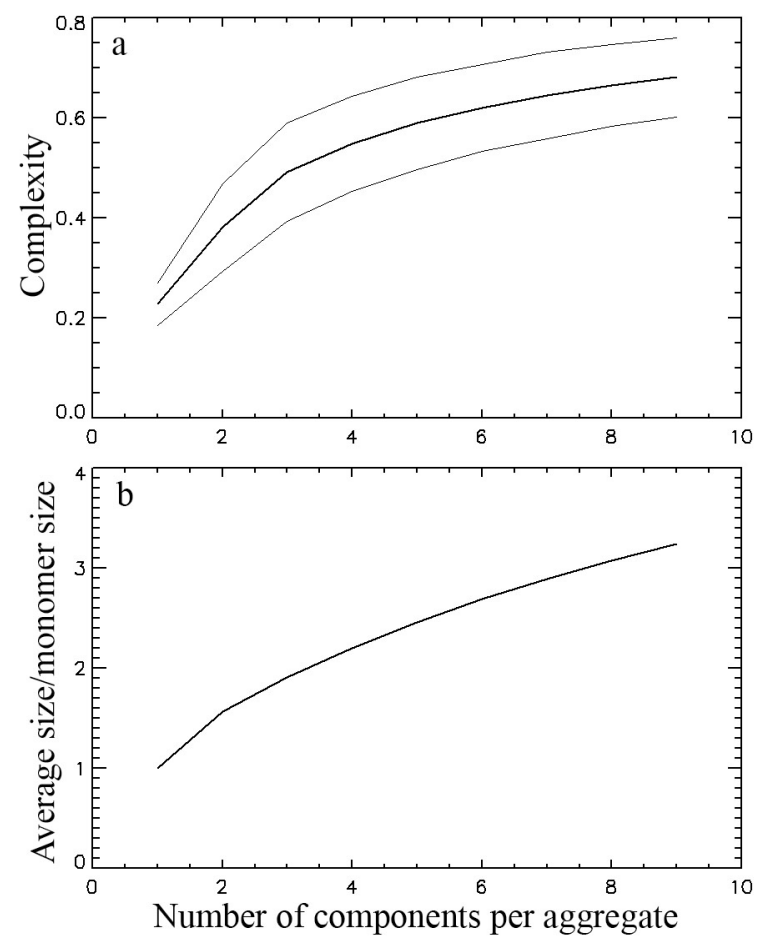

388

389 

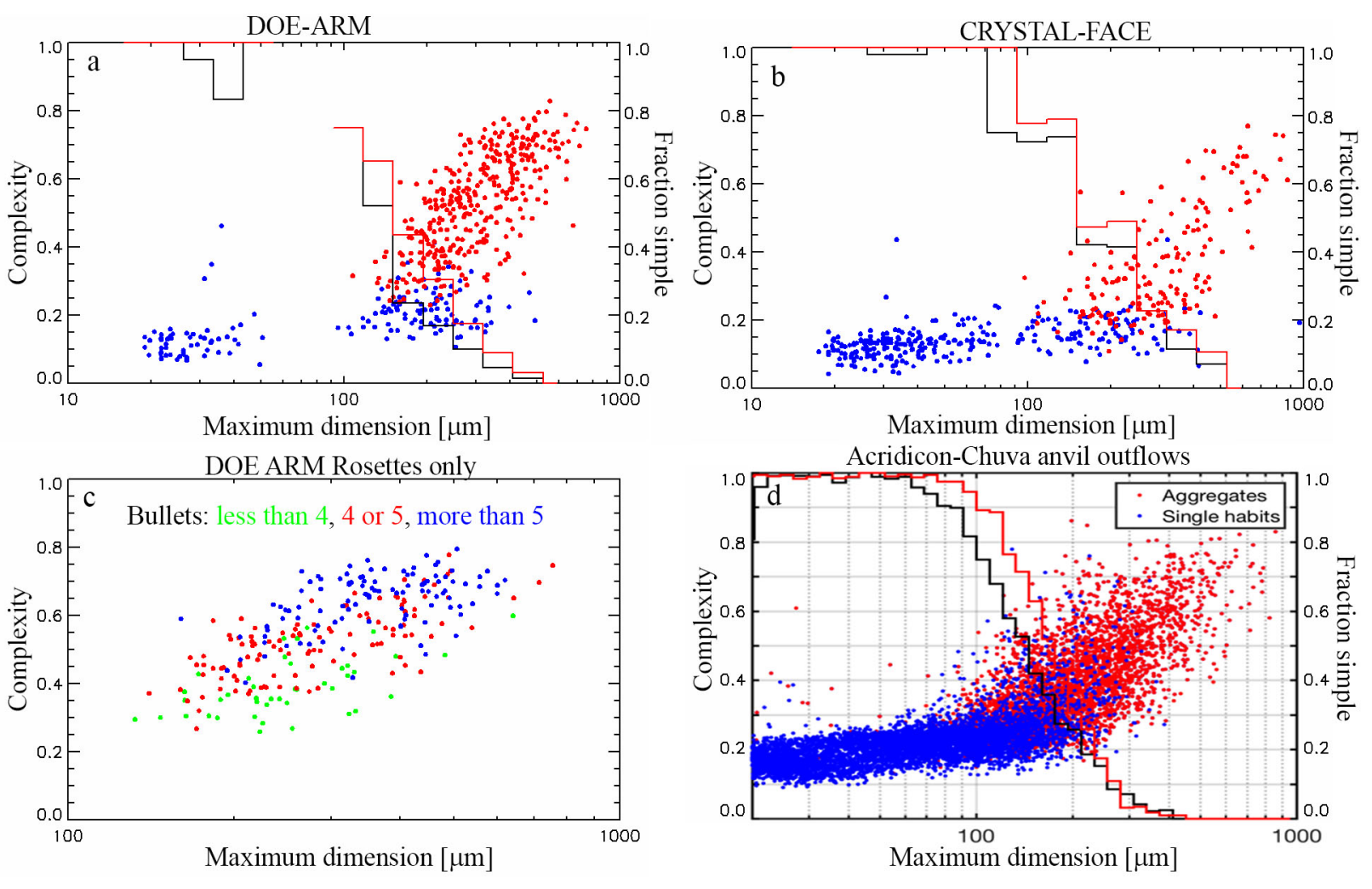
Confidential manuscript submitted to Geophysical Research Letters
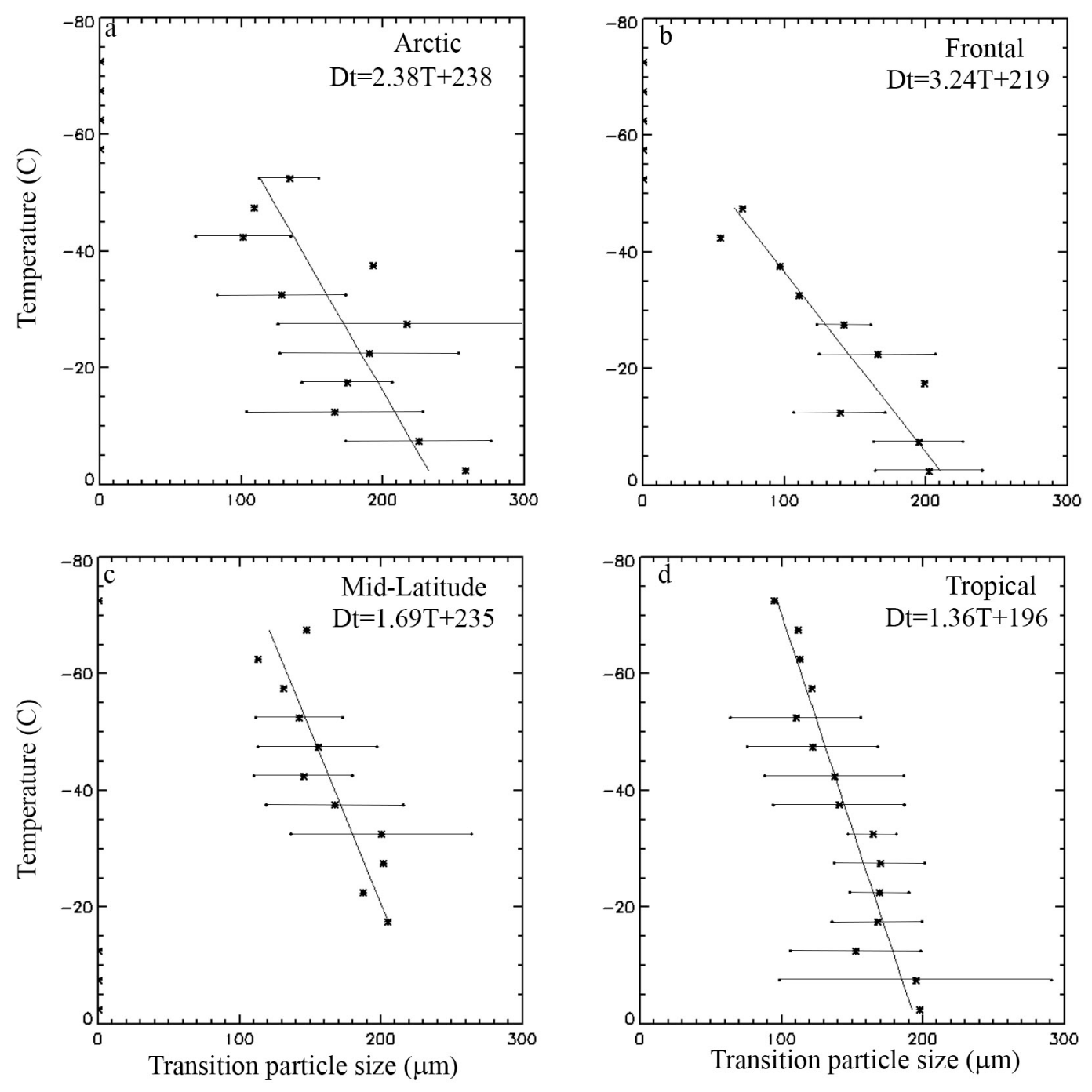